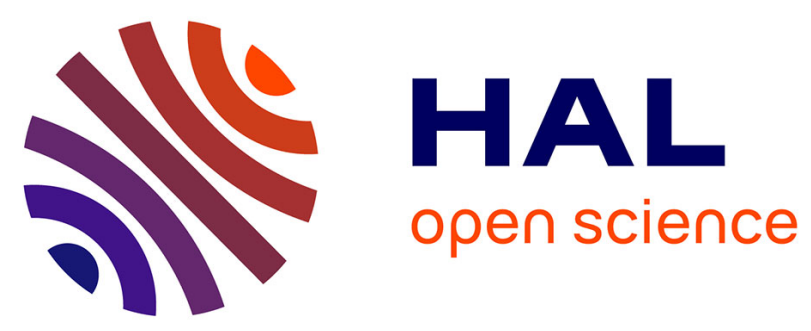

\title{
A phase-shift self-oscillating stereo class-D amplifier for battery-powered applications
}

Alexandre Huffenus, Gaël Pillonnet, Nacer Abouchi, Frédéric Goutti, Vincent Rabary, Cécile Specq

\section{- To cite this version:}

Alexandre Huffenus, Gaël Pillonnet, Nacer Abouchi, Frédéric Goutti, Vincent Rabary, et al.. A phaseshift self-oscillating stereo class-D amplifier for battery-powered applications. IEEE International Symposium on Circuits and Systems, IEEE, 2010, Paris, France. pp.4, 10.1109/ISCAS.2010.5537458 . hal-01103679

\section{HAL Id: hal-01103679 \\ https://hal.science/hal-01103679}

Submitted on 15 Jan 2015

HAL is a multi-disciplinary open access archive for the deposit and dissemination of scientific research documents, whether they are published or not. The documents may come from teaching and research institutions in France or abroad, or from public or private research centers.
L'archive ouverte pluridisciplinaire HAL, est destinée au dépôt et à la diffusion de documents scientifiques de niveau recherche, publiés ou non, émanant des établissements d'enseignement et de recherche français ou étrangers, des laboratoires publics ou privés. 


\section{A Phase-Shift Self-Oscillating Stereo Class-D Amplifier for Battery-Powered Applications}

\author{
Alexandre Huffenus, Gaël Pillonnet, Nacer Abouchi \\ Lyon Institute of Nanotechnology \\ CPE Lyon \\ Villeurbanne, France \\ inl@.cpe.fr
}

\author{
Frédéric Goutti, Vincent Rabary, Cécile Specq \\ AMPS \\ STMicroelectronics \\ Grenoble, France \\ frederic.goutti@st.com
}

\begin{abstract}
This paper presents a highly efficient stereo audio amplifier, based on a self-oscillating modulator. This modulation scheme has been analyzed and shows to have a higher bandwidth and error correction than standard Pulse Width Modulation (PWM). A practical implementation in CMOS 0.25um technology has been done to validate our theoretical and simulation results. Our amplifier demonstrated a Total Harmonic Distortion plus Noise (THD+N) as low as $0.07 \%$, current consumption is $3.88 \mathrm{~mA}$ at $3.6 \mathrm{~V}$ (stereo) and the efficiency reaches $88 \%$ into $80 \mathrm{hms}$. The integrated circuit measures $1.6 \times 1.6 \mathrm{~mm}$ and is able to work at supply voltages from $2.3 \mathrm{~V}$ to $5.5 \mathrm{~V}$.
\end{abstract}

\section{INTRODUCTION}

Battery-powered applications bring severe challenges on current consumption. This explains the wide use of switching (Class-D) amplifiers for the audio amplification part. Class-D modulation has several advantages compared to Class-AB, especially the lower idle current and the much higher efficiency, both leading to an increased playback time. One problem with Class-D amplifiers, though, is their inherent non-linearity.

The most common Class-D modulation scheme is carrierbased PWM [1, 2, 3, 4]. In order to reduce the effects of nonlinearities and to improve the Power Supply Rejection Ratio (PSRR), a feedback loop is added around the amplifier. While being easy to implement and having a constant switching frequency, its drawback is a limited loop bandwidth hence a lower output error correction and a higher THD.

Self-oscillating modulators have an increased bandwidth compared to PWM ones [4, 5], leading to a reduced output error thus a lower THD. Also, there is no need for a triangle wave or sawtooth oscillator anymore so its current consumption can be spared.

This paper will show the analysis and realization of a selfoscillating amplifier. Section II will present the different PWM modulation schemes, carrier-based and self-oscillating, and compare their characteristics. The theory of phase-shift self-oscillating modulation will be explained in Section III, as well as the specificities for a mobile stereo amplifier. The realization of the integrated circuit will be shown in Section IV with a focus on the modulator stage and the differences with a carrier-based PWM architecture. Section V will present the measured performance and, finally, a conclusion will be drawn.

\section{TOPOLOGICAL COMPARISON}

\section{A. PWM Modulation (Carrier-Based)}

Analog PWM modulation can be found in various forms like NADS, NABD, NBDD [1, 2, 3] all of them having the same maximum loop bandwidth equal to $f_{s w} / \pi[4]$ for stability issues. Here there is a sawtooth (or triangle wave) signal on the comparator, but no feedback filter, delay or hysteresis. With a first order integrator as the error amplifier, and a switching frequency of $300 \mathrm{kHz}$ this leads to a loop gain of about $40 \mathrm{~dB}$ at $1 \mathrm{kHz}$.

Fig. 1 and Fig. 2 show the structure and block diagram that are applicable to all the topologies listed here.

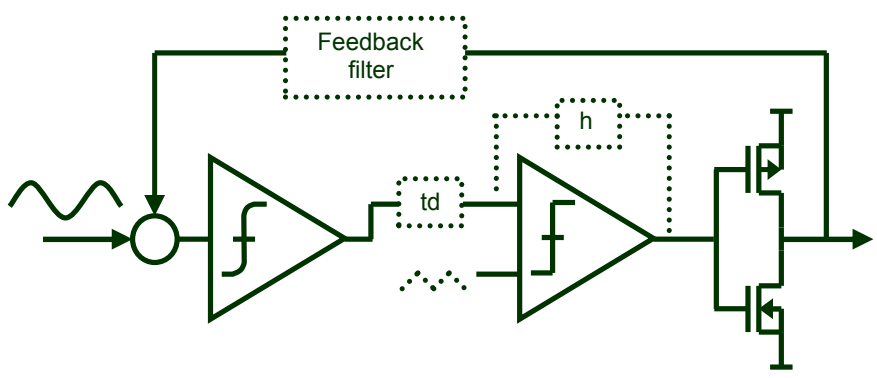

Figure 1. Class-D amplifier general structure

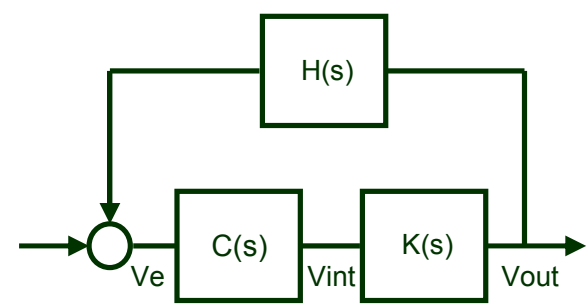

Figure 2. Class-D amplifier block diagram 


\section{B. Hysteresis-Based Self-Oscillating}

Self-oscillating modulators can be realized in different ways, the first one is hysteresis-based modulation $[4,5]$. It is based on a hysteresis window $\left(\mathrm{h}=\mathrm{Vdd} / \mathrm{V}_{\text {hyst }}\right)$ around the error signal, when the latter reaches the top or the bottom of the window the output stage toggles its state.

It should be noted that self-oscillating modulation leads to a non-constant switching frequency, depending on the modulation index $\mathrm{M}$ (defined between +1 and -1 and related to the Duty-Cycle D):

$$
M=2 \cdot D-1
$$

Nearly constant frequency operation has been shown, at the expense of a slightly increased system complexity [6].

\section{Delay Based Self-Oscillating}

Another kind of modulator is the delay-based one [4], its operation relies on a time delay $t_{d}$ in the loop that generates phase of:

$$
\angle\left(t_{d}(f)\right)=360 \cdot t_{d} \cdot f
$$

The closed-loop system turns into an oscillator when the following conditions are met [4]:

$$
\begin{gathered}
|C(f) \cdot K(f) \cdot H(f)|=1 \\
\angle(C(f) \cdot K(f) \cdot H(f))=180^{\circ}
\end{gathered}
$$

\section{Phase-Shift Self-Oscillating}

In this kind of modulation, the loop is made of a combination of gains, poles and zeros to define a frequency where the oscillation criterions (3) and (4) are met.

A comparison of the switching frequency variation for diferent self-oscillating modulations is shown in Fig. 3.

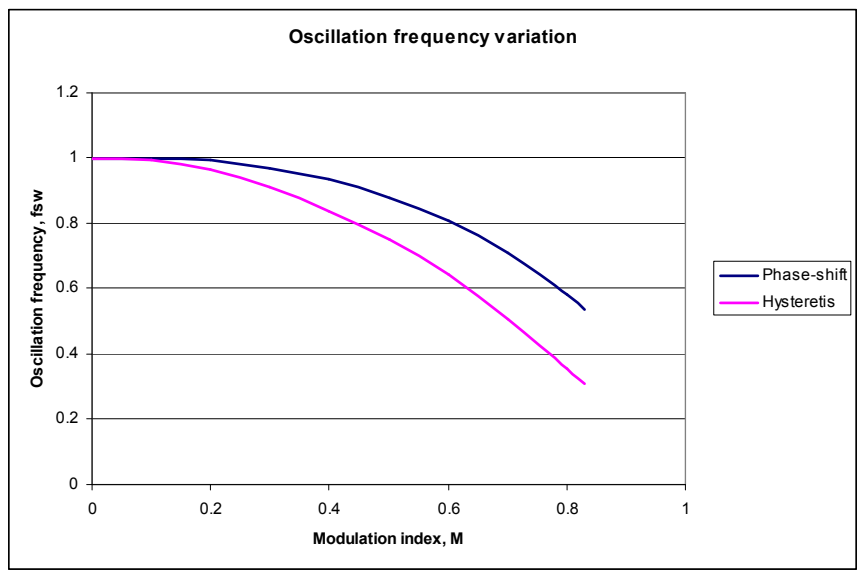

Figure 3. Frequency Variation (simulation results)
TABLE I. MODULATION SCHEMES COMPARISON

\begin{tabular}{|c|c|c|c|}
\hline Modulator & Osc. Freq. $\mathbf{f}_{\mathrm{sw} 0}$ & $\mathbf{f}_{\mathrm{sw}}$ Variation & Loop Gain \\
\hline Carrier-based & Fixed & None & $\frac{f_{s w}}{\pi \cdot f}$ \\
\hline Hysteresis & $\frac{1}{4 \cdot h \cdot \tau_{\mathrm{int}}}$ & $f_{s w 0}\left(1-M^{2}\right)$ & $\frac{12}{\pi^{2}} \cdot\left(\frac{f_{s w}}{f}\right)^{2}$ \\
\hline Delay & $\frac{1}{4 \cdot t_{d}}$ & $f_{s w 0}\left(1-M^{2}\right)$ & $\frac{2 \cdot f_{s w}}{\pi \cdot f}$ \\
\hline Phase-shift & When phase $=180^{\circ}$ & $\begin{array}{c}\text { No theoretical } \\
\text { work so far }\end{array}$ & $\frac{f_{s w}}{f}$ \\
\hline
\end{tabular}

Table 1 lists the characteristics of the different modulation schemes. It shows that the hysteresis-based topology has the highest theoretical gain, but also the highest variation in switching frequency. The latter is a problem when the amplifier is often used at its full excursion (as it is for mobile applications) since the switching frequency can fall down into the audio band. Also, any delay in the loop (comparator, output stage...) has an impact on the loop gain that gets reduced to a first order function [4].

The switching frequency variation is an important concern for mobile phone applications, and has led the authors to the choice of the phase-shift self-oscillating modulation. Its detailed theory of operation will be depicted in the next section.

\section{Phase-Shift Self-Oscillating Theory}

\section{A. Oscillation Criterion}

As explained in section II, the phase-shift modulation scheme relies on the Barkhausen criterion (3) and (4) to oscillate. A more recent theory is explained in [7]. A Class-D amplifier as shown in Fig. 1 can be modeled like the system in Fig. 2. In our implementation the feedback filter is a single pole at $f_{c}$ (above the audio band) and the integrator has a bandwidth $\mathrm{f}_{0}$, while the switching stage (comparator, output stage drivers and output stage) can be modeled as a gain $\mathrm{K}$, ratio of its output and input amplitude.

$$
K(f)=\frac{\operatorname{Vout}(f)}{\operatorname{Ve}(f)}=\frac{V d d}{\operatorname{Ve}(f)}
$$

The loop gain is then:

$|G(f)|=|H(f) \cdot C(f) \cdot K(f)|=\left|\frac{V_{\mathrm{int}}(f)}{V_{\text {out }}(f)} \cdot \frac{V_{e}(f)}{V_{\mathrm{int}}(f)} \cdot \frac{V d d}{V_{e}(f)}\right|$

At $\mathrm{f}=\mathrm{f}_{\mathrm{sw}}, \operatorname{Vout}(\mathrm{s})$ is equal to $\operatorname{Vdd},|\mathrm{G}(\mathrm{f})|$ is then equal to 1 .

$$
\left.\angle G(f)=90+\angle \frac{1}{1+j \cdot f / f_{c}}\right)+360 \cdot f \cdot t_{d}
$$


At the switching frequency, the loop gain is always unity. The oscillation criterion is then only tailored by the phase condition: the placement of poles and zeros in the transfer function. The system presented in this paper only contains two poles: one in the feedback path and an integrator as the error amplifier. The delays in the loop (mostly the comparator propagation delay) provide the excess phase to reach $180^{\circ}$.

\section{B. 3-Levels "Filterless" (Ternary) Modulation}

For mobile applications, a well-spread technique is to use a 3-Levels modulation (NBDD) instead of the normal 2-Levels one (NADD) as in Fig. 4 [1, 2, 3, 8 ,9]. This reduces the output high frequency content and permits the use of a more compact output filter. Using a H-bridge output controlled by two modulators, receiving input signals in opposite phase will generate a 3-Levels output. Because of components mismatch, the two paths will not work at the exact same frequency and phase and the output HF spectrum will not be optimally reduced. Previous work $[10,11]$ showed a coupling scheme that provides satisfactory results and that is used here.
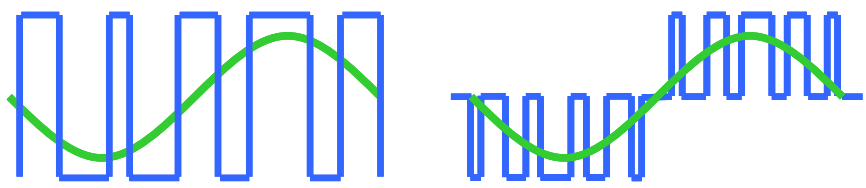

Figure 4. 2-Levels and 3-Levels modulations

\section{Stereo Application and Idle Tones (Beating)}

More and more portable devices are equipped for stereo. One problem arises with the implementation of two audio channels on the same silicium die: components mismatch will result in two different oscillation frequencies $f_{s w 1}$ and $f_{s w 2}$. Even a small parasitic coupling will produce beating at $\mid f_{\mathrm{sw}^{-}}{ }^{-}$ $\mathrm{f}_{\mathrm{sw} 2} \mid$. This frequency will quite likely be in the audio band and will be heard at idle. A coupling between both channels (like in section III.B) would compromise the crosstalk too much. The solution is to offset $f_{\text {sw1 }}$ and $f_{s w 2}$ by more than the audio band, like $30 \mathrm{kHz}$, to push the beating out of the audible range.

\section{PRACTICAL IMPLEMENTATION IN $0.25 \mu \mathrm{M}$ CMOS}

\section{A. Audio Chain}

Standalone mobile Class-D amplifiers have a linear preamplifier in front of the switching stage [8,9]. It is a differential amplifier used to reject the input common mode, to provide the gain and to set the input impedance. Due to mismatch in the feedback resistors, this stage limits the PSRR to around $60-70 \mathrm{~dB}$. Fig. 5 shows the signal chain as realized.

\section{B. Integrator and Feedback Loop}

The integrator amplifier is a two-stage Class-A ota. $\mathrm{R}_{\mathrm{fbA}}$, $\mathrm{R}_{\mathrm{fbB}}$ and $\mathrm{C}_{\text {int }}$ define the integrator's $0 \mathrm{~dB}$ point $\mathrm{f}_{0}$.

$R_{i n}, R_{f b A}$ and $R_{f b B}$ also define much of the noise performance of the circuit so their value should not be too high. However, a too low value would result in high feedback currents and high integrator OTA consumption.

Equation 6 shows that the gain at $\mathrm{f}_{\mathrm{sw}}$ is constant and shared between the integrator $\mathrm{C}(\mathrm{f})$ and the comparator $\mathrm{K}(\mathrm{f})$. If the integrator has a high $\mathrm{f}_{0}$ its output swing $\mathrm{Ve}$ will be large and the comparator will have a low gain $\mathrm{K}(\mathrm{f})$, reciprocally if $\mathrm{f}_{0}$ is low then Ve will be small and $K(f)$ will be large. This means that the choice of $f_{0}$ has no impact on $f_{\text {sw }}$ and is a tradeoff between large capacitors and noise sensitivity on one side and ota slew rate and excursion requirements on the other side.

\section{Power Stage}

The amplifier's output stage is a H-bridge made of PMOS transistors for the upper side, and NMOS transistors on the low side. Their $\mathrm{R}_{\mathrm{DSON}}$ are about hundred milliohms each. A lower $\mathrm{R}_{\mathrm{DSON}}$ would require larger output transistors so the efficiency would be higher but also the IC area use and idle current consumption. A $0.25 \mu \mathrm{m}$ process with thick oxide transistors is used to keep the circuit compatible with cell phone batteries (2.3-4.8V) and 5V applications like laptops.

\section{Changes from a Carrier-Based PWM Amplifier}

With a Class-D PWM amplifier as a starting point for this project, the changes made are the following:

- Removing the oscillator and sawtooth generation

- Connecting the positive comparator input to the common mode voltage instead of the sawtooth signal.

- $\quad$ Splitting the feedback resistor in two, with a capacitor between the two parts to create the feedback pole.

\section{PRACTICAL MEASUREMENTS}

\section{A. Audio Performance}

The THD+Noise vs. Output Power is plotted in Fig. 6 in mono operation, compared with a carrier-based PWM configuration (all other building blocks are the same). Fig. 7 shows the stereo operation, compared to the amplifier with only one channel used. In stereo the performance is reduced at high output levels, a parasitic coupling between the channels is likely to be the cause of this problem.

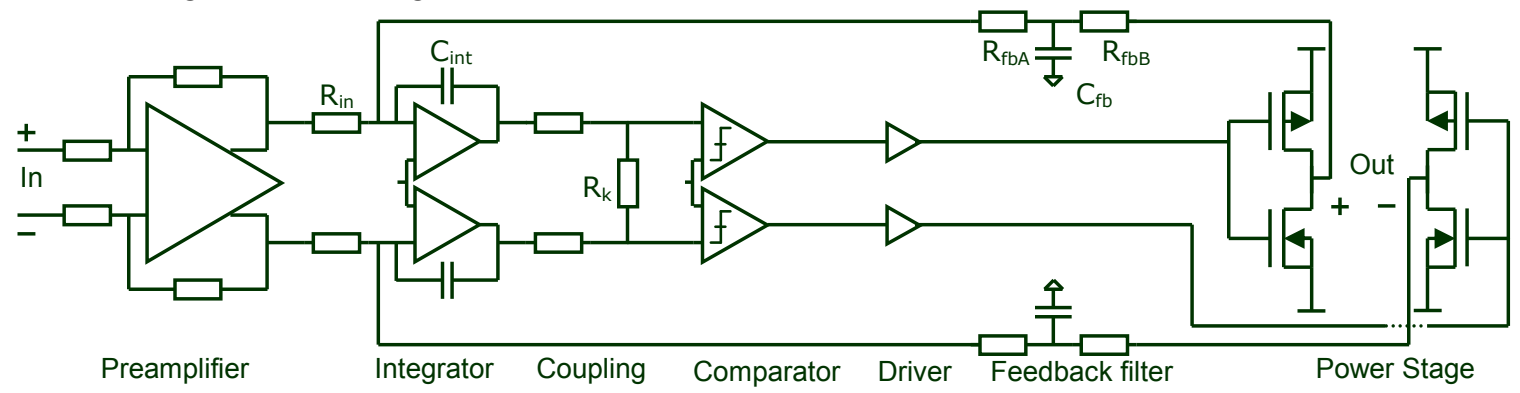

Figure 5. Audio chain (one channel shown) 


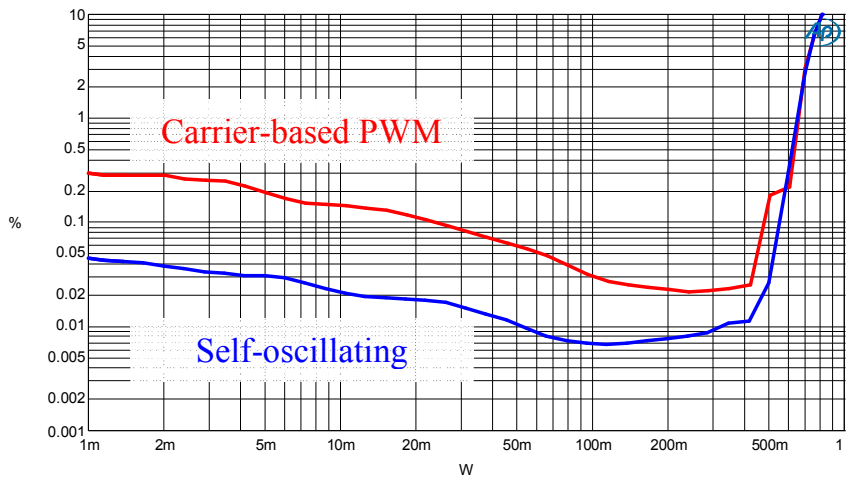

Figure 6. THD $+\mathrm{N}$ vs Output Power, mono, $1 \mathrm{kHz}, 8 \Omega$ load

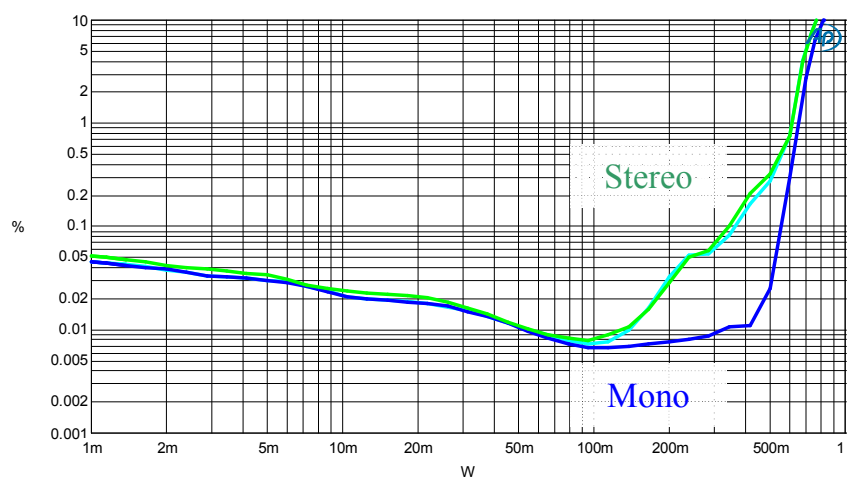

Figure 7. $\mathrm{THD}+\mathrm{N}$ vs Output Power, stereo, $1 \mathrm{kHz}, 8 \Omega$ load

\section{B. Switching Behavior: Coupling}

The output PWM waveforms at idle are shown in Fig. 8, for both polarities of the H-Bridge output. They have the same frequency and phase, showing that the coupling works.

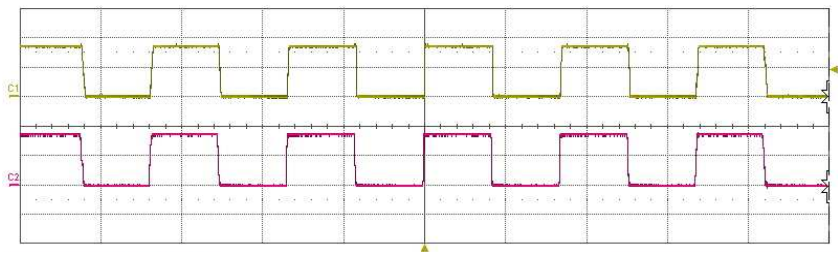

Figure 8. Outputs at idle (top: OUT+, bottom: OUT + )

\section{Summary}

Table 2 summarizes the other characteristics and performance. A layout view of the IC is shown in Fig. 9.

TABLE II. AMPLIFIER CHARACTERISTICS

\begin{tabular}{|c|c|c|}
\hline Parameter & Phase-shift & Conditions \\
\hline Vdd & $2.3-5.5 \mathrm{~V}$ & \\
\hline Istandby & $0.6 \mu \mathrm{A}$ & Vdd $=3.6 \mathrm{~V}$ \\
\hline Icc mono & $2.04 \mathrm{~mA}(\mathrm{~L}) 1.99 \mathrm{~mA}(\mathrm{R})$ & 1 channel $\mathrm{ON}, \mathrm{Vdd}=3.6 \mathrm{~V}$ \\
\hline Icc stereo & $3.88 \mathrm{~mA}(\mathrm{~L}+\mathrm{R})$ & Both channels $\mathrm{ON}, \mathrm{Vdd}=3.6 \mathrm{~V}$ \\
\hline Fsw & $296 \mathrm{kHz}(\mathrm{L}) 268 \mathrm{kHz}(\mathrm{R})$ & Vdd $=3.6 \mathrm{~V}$, at idle \\
\hline$\Delta F \mathrm{sw}$ & $28 \mathrm{kHz}$ & Vdd $=3.6 \mathrm{~V}$, at idle \\
\hline Efficiency & $88 \%$ & Vdd $=3.6 \mathrm{~V}$, OOhms load \\
\hline PSRR & $65 \mathrm{~dB}$ & Limited by the preamplifier \\
\hline Noise & $26 \mu \mathrm{V}$ & A weighted, bdB gain \\
\hline Size & $1.6 x 1.6 \mathrm{~mm}$ & WCSP package \\
\hline Process & $0.25 \mu \mathrm{m}$ & Thick oxide transistors used \\
\hline
\end{tabular}

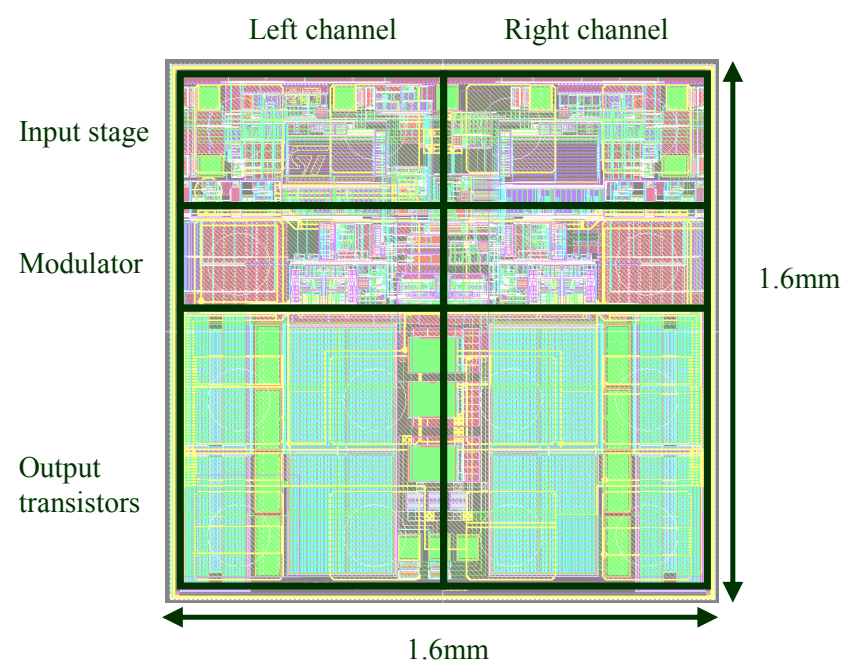

Figure 9. IC layout view

\section{CONCLUSION}

The study of different modulation schemes showed that the phase-shift self-oscillation one is an interesting option for battery-operated systems. Improving the THD figures was the main target and has been achieved, by almost a decade compared to carrier-based PWM. Despite the increased THD in stereo mode, the theoretical and practical results are encouraging for the use of new modulation schemes in mobile Class-D amplifiers.

\section{REFERENCES}

[1] J.D. Martin, "Theoretical efficiencies of Class-D Power Amplifiers", Proc. IEE., Vol . 117, pp. 1089-1090, 1970.

[2] J. Vanderkooy, "New Concepts in Pulse-Width Modulation", presented at the $97^{\text {th }}$ AES Convention, Preprint 3886, Nov. 1994.

[3] K. Nielsen, "A Review and Comparison of Pulse Width Modulation (PWM) Methods for Analog and Digital Input Switching Power Amplifiers", presented at the $102^{\text {nd }}$ AES Convention, Preprint 4446, March 1997.

[4] M. Berkhout, "Class-D Audio Amplifiers in Mobile Applications", IEEE Internationnal Synopsium on Circuit and Systems, pp. 11691172, May 2009.

[5] G. Pillonnet, N. Abouchi, R. Cellier, A. Nagari, “A 0.01\% THD, 70dB PSRR Single Ended Class D using variable hysteresis control for headphone amplifiers", IEEE Internationnal Synopsium on Circuits and Systems, pp. 1181-1184, May 2009.

[6] S. Poulsen, M.A.E. Andersen, "Hysteresis Controller with Constant Switching Frequency", IEEE Transactions on Consumer Electronics, Vol. 51, Issue 2, pp. 688-693, May 2005.

[7] B. Putzeys, "Globally Modulated Self-Oscillating Amplifier with Improved Linearity", presented at the $37^{\text {th }}$ AES Conference, Aug. 2009.

[8] STMicroelectronics, TS4962M datasheet

[9] Texas Instruments, TPA2012d2 datasheet

[10] T. Piessens, M. Steyaert, "Oscillator Pulling and Synchronisation Issues in Self-Oscillating Class D Power Amplifiers", Proceedings of the $29^{\text {th }}$ European Solid-State Circuits Conference, pp. 529-532, Sept. 2003.

[11] L. Soo-Hyoung et al., "A 2W, 92\% efficiency and $0.01 \%$ THD+N class-D audio power amplifier for mobile applications, based on the novel SCOM architecture", Proceedings of the IEEE Custom Integrated Circuits Conference, Oct. 2004. 